\title{
MINIMIZING THE DISCREPANCY BETWEEN THE CLINICAL KNOWLEDGE AND PERFORMANCE OF MEDICAL GRADUATES FOR IMPROVEMENT OF THE QUALITY OF OUR HEALTH CARE SYSTEM
}

\author{
Badhu BP* \\ Professor of Ophthalmology, Birat Medical College and Teaching Hospital, Kathmandu University, Nepal \\ https://orcid.org/0000-0001-8381-199X
}

\begin{abstract}
Citation
Badhu BP. Minimizing the Discrepancy Between the Clinical Knowledge and Performance of Medical Graduates for Improvement of the Quality of Our Health Care System
\end{abstract}

\section{DOI: https://doi.org/10.3126/bjhs.v5i3.33678}

The ultimate outcome of the health care system depends on the quality of the clinical performance of service providers. Maintaining the expected standards of clinical skills of medical graduates is primarily the responsibility of teaching institutions and the vital role of education monitoring bodies in this regard cannot be ignored.

In the field of medical education, the ultimate goal of a university is to produce competent and compassionate graduates with reasonably adequate knowledge, professional skills and a caring attitude. Developing a prototype for assessment of these domains is important for meaningful comparison of clinical performance of future health work force to achieve the desired outcomes and quality control of health care services. ${ }^{1}$ Today there are several universities and institutes in Nepal that impart training to the undergraduate and post-graduate medical students. Additionally, many specialists trained abroad join the medical fraternity providing health care in the country.

The discrepancy between the clinical knowledge and performance of the service providers can be expected to exist particularly because of differences in university entry criteria, course and curricula as well as teaching methodology and methods of evaluation. There can be several other contextual factors like the socio-cultural and linguistic differences between the places where a graduate studied and where he/she is supposed to deliver service.

It can realistically be assumed that minimizing this discrepancy between knowledge and performance of medical graduates can be helpful in quality improvement ofthe health care system. The question is how this can be achieved.

The qualities of an ideal physician include compassion, empathy, professionalism, etiquette and deontological norms. Such qualities can be learned by observing the performance of senior colleagues who are recognized for such qualities by the established institutions and the co-workers. The positive impact of patient feedback on the performance of qualified doctors has been reported. ${ }^{2}$
We have witnessed every year the increasing trend in the ratio of number of eligible applicants after the entrance exams and number of students enrolled into the higher medical schools. A proportionately increasing number of medical schools with an appropriate control of quality can address the gap between the requirement and the availability of qualified health care providers.

So as to avoid the discrepancy between the knowledge and the clinical acumen, communication skills and professionalism of the graduates, our medical schools should maintain and strictly follow the universal standards of education. Most of the examinations in medical schools evaluate the cognitive domain of medical education through the theory questions. The practical exams include case presentation, OSCE stations and viva voce. Less attention is given to actual performance in terms of communication with patients and common clinical procedures.

The role of an honestly maintained log-book verified by internal faculty members can be a useful tool for unbiased assessment of a student by external examiners during the final examinations. In case any question arises with respect to the integrity of the log-book, the students can be asked to demonstrate the performance.

The licensing medical exams in Nepal also mainly focus on knowledge evaluation. Somehow, the other domains of education, particularly the psychomotor and affective ones, are ignored. Considering the diversity in the contents of medical curricula, teaching and examination methods of medical schools, the licensing exam that is common for all can achieve its goal by inculcating practical performance components in its evaluation.

In conclusion, the discrepancy between the theoretical knowledge andclinical performance of medical graduates for quality improvement in the health care system can be minimized through necessary changes in the medical curricula and teaching and assessment methodologies.

\section{REFERENCE}

1. Center for Health Policy Studies, Columbia, MD. https://aspe.hhs. gov/report/performance-improvement-1996/understanding-andchoosing-clinical-performance-measures-quality-improvementdevelopment-typology. Accessed 22.12.2020
2. Baines, R., Regan de Bere, S., Stevens, S. et al. The impact of patient feedback on the medical performance of qualified doctors: a systematic review. BMC Med Educ 18, 173 (2018). https://doi.org/ 10.1186/ s12909-018-1277-0 